\title{
Editor-in-Chief: thank you and farewell
}

\author{
Gian Franco Gensini
}

Published online: 12 May 2009

(C) SIMI 2009

As this is my last issue as Editor-in-Chief of Internal and Emergency Medicine, I would like to reflect on the past, and look ahead to the future of this journal.

Since 2006 the Official Journal of the Italian Society of Internal Medicine (SIMI) has been published in English, and entitled Internal and Emergency Medicine. To further increase the international visibility and to improve its diffusion among a wider international community, the journal changed to a different publisher in 2007, and since this time, the journal has been published by Springer.

The transition to the new, international publisher entailed some important changes for the journal. Since that time the journal has been published both in print and online at the publisher's platform: SpringerLink. SpringerLink, the world's most comprehensive online collection of scientific, technological and medical journals, books and reference works, is guaranteeing maximum exposure and visibility for the journal.

By implementation of the electronic manuscript submission system Editorial Manager, the journal has had a significant improvement of the turnaround time for the review process of each manuscript, as well as a more rapid electronic publication. During the past several years, the number of manuscripts submitted to Internal and Emergency Medicine has increased significantly, with an incremental increase of 54\% in 2008 over 2007. Within the first months of 2009 (January-March), a further increase in

G. F. Gensini $(\square)$

Editor-in-Chief, Internal and Emergency Medicine, Department of Critical Care Medicine and Surgery, University of Florence and Azienda Ospedaliero-Universitaria, Careggi, Viale Morgagni 85, 50134, Florence, Italy

e-mail: g.gensini@dac.unifi.it submitted manuscripts has occurred, so there will be another significant increase for the year 2009.

On the basis of these results, we decided to raise the frequency of the journal publication, and so starting in 2009, Internal and Emergency Medicine is published 6 instead of 4 times a year. Moreover, with the first issue of 2009 , the journal has a newly designed cover.

During the last few years, Internal and Emergency Medicine has continuously improved not only in terms of scientific impact, but also regarding its quality as an international journal. I therefore am pleased to announce that Internal and Emergency Medicine has been accepted by Thomson Reuters for inclusion in Science Citation Index Expanded and Journal Citation Reports/Science Edition, beginning with volume 1, issue 1, 2006. That means it will receive an Impact Factor in 2008. This is a great success, which would not have been possible without the support and dedication of our Editorial Board, the Italian Society of Internal Medicine (SIMI), the Springer team and many of you, our colleagues, who have reviewed so many manuscripts over the years, and helped not only the authors to improve their papers, but also us to finally select the best manuscripts for our journal. So I would like to thank you all, and last but not least all the Internal and Emergency Medicine readers.

My special thanks go to Domenico Prisco for his commitment and successful work over the past few years. I am very glad to announce that Domenico Prisco has been assigned by the Italian Society of Internal Medicine to be Editor-in-Chief of Internal and Emergency Medicine from the next issue.

I wish him and his coworkers every possible success. 